\title{
Kantor, Duchamp e os objetos ${ }^{1}$
}

Valmor Beltrame

Maria de Fátima de Souza Moretti

RESUMO: Este breve paralelo que faço entre a obra e o pensamento do polonês Tadeusz Kantor e do francês Marcel Duchamp, tem como especificidade a relação que os dois artistas estabelecem em suas obras com os objetos ou ready-mades. Essa relação aponta caminhos para pensar o Teatro de Objetos, uma vertente do Teatro de Formas Animadas.

PALAVRAS-CHAVE: 1. Objeto; 2. Kantor; 3. Duchamp.

O paralelo entre esses dois artistas que iniciaram suas carreiras como pintores e mudaram de profissão, embora jamais tenham deixado de lado a pintura, surgiu a partir da leitura de alguns textos como Castelo da Pureza de Otávio Paz, Kantor ao présent de Guy Scarpeta e outros. Kantor voltou-se para o mundo do teatro, das performances, da cenografia, e Duchamp, segundo Otávio Paz, "trocou a pintura-pintura pela pinturaidéia" e voltou-se para o mundo dos jogos, especializando-se no jogo de xadrez.

Ambos, imbuídos da ideologia da época, de um pós-guerra, eram influenciados pelo desejo transgressor do surrealismo e do dadaísmo.

O ready-made, cuja escolha não é ditada por qualquer tipo de prazer estético, e sim fundamentada numa relação de indiferença visual, acompanhada por uma ausência total de bom ou mau gosto, seria uma forma de caracterizar essa nova postura. Duchamp nos conta como surgiu a palavra ready-made ligada à sua obra:

\footnotetext{
A palavra ready-made só apareceu em 1915, quando fui aos Estados Unidos. Ela me interessou como palavra, mas quando coloquei uma roda de bicicleta sobre um banco, o garfo invertido, não havia ainda qualquer idéia de readymade ou coisa parecida, era apenas uma forma de distração. (DUCHAMP apud CABANNE, 1987, p. 79)
}

\footnotetext{
${ }^{1}$ Artigo resultado de pesquisa efetuada por Maria de Fátima de Souza Moretti, Mestre em Literatura e Doutoranda do Curso de Pós-Graduação em Literatura - UFSC, Professora Colaboradora do Departamento de Artes Cênicas - CEART/UDESC, no Grupo de Estudos sobre Teatro de Animação. Colaboradora do Programa de Extensão Formação Profissional no Teatro Catarinense, sob a orientação do Prof. Dr. Valmor Beltrame - DAC/CEART/UDESC.
} 
Para Duchamp, o ready-made é uma apropriação do que já está feito, sendo a transposição dos objetos uma finalidade prática e não artística. São objetos de ordem industrial, elevados à categoria de obras de arte. São objetos anônimos em que o gesto gratuito do artista, pelo fato de escolhê-lo, converte-o em obra de arte, como por exemplo a Fontaine-Urinoir", o produto escolhido e manufaturado que perdeu sua função primitiva ao ser exposto com um giro de 90 graus. Ao mesmo tempo, esse gesto gratuito dissolve a noção de obra de arte, é a antiarte. $O$ interesse que leva à escolha desse ou daquele objeto não é plástico, mas crítico ou filosófico. Com efeito, não há a postulação de um valor novo, apenas uma crítica ativa contra a obra de arte assentada na idéia de valor. Segundo SantAnna (2003), este procedimento é uma estratégia de deslocamento, sendo este um traço da personalidade de Duchamp, que o faz não necessariamente por estética, mas aparece em tudo o que fez, até seus trocadilhos são metonímicos da mesma maneira que quis substituir a obra pela idéia da obra.

Kantor, de certa forma, quando era menino, já tinha gosto pela transformação lúdica dos objetos, pois já construía trens com caixas de sapatos e fazia das igrejas de sua cidade seu espaço teatral favorito.

Mais tarde, em seus espetáculos, se utiliza de objetos encontrados por acaso, retira dos objetos a sua função utilitária, sua significação original. Em Kantor, a metáfora é sempre explorada ao partir da proposta de utilização de um objeto como significante de outro: Uma máquina fotográfica em determinado momento se transforma em metralhadora.

O método de trabalho de Kantor se baseia na relação entre o ator e o objeto. Nos espetáculos tradicionais o objeto é tido como um "acessório" que ajuda na interpretação do ator, na vida do personagem. Kantor sempre criticava a forma com que os atores tratavam o objeto no teatro tradicional. Sua utilização era sempre secundária. Ele reconhece a importância dos objetos: não os utiliza simplesmente, anexa-os aos espetáculos, faz deles personagens como os atores. Assim como Duchamp, ele tira do objeto seus atributos tradicionais, estéticos ou formais, fazendo deles um ready-made. Por isso lhes dá um novo peso de existência.

Para Kantor é necessário respeitar o objeto, tratá-lo como um objeto vivo da vida corrente, e não considerá-lo apenas como um acessório de teatro. Ele seguidamente repetia que o objeto era mais importante que os atores. Para ele, o ator, o objeto e a música eram os elementos fundamentais na construção do espetáculo. 
Duchamp e Kantor tinham como proposta a desconstrução do objeto, o uso do objeto como impulso criador, os ready-mades. Para eles o objeto era o impulso e a obra transgressora.

Nos espetáculos de Kantor, é possível perceber que os diferentes elementos plásticos, como objetos, luz, espaço cênico, e os atores possuem um mesmo status.. Quanto a sua obra ele diz:

Eu não dissocio as minhas pesquisas teatrais das minhas experiências plásticas [...]. Eu acredito que devemos sempre considerar a arte em sua totalidade e que a especialização profissional e a busca de uma pureza e de uma especificidade resultam, na maioria dos casos, em práticas muito particulares e duvidosas. (KANTOR, 1977, p. 26)

Depois de anos de trabalho no teatro profissional como cenógrafo, Kantor rejeita as regras deste, põe em dúvida as existências do ator e do teatro na sua forma tradicional e impõe sua própria visão. Seu talento de pintor é decisivo na definição e estética dos espetáculos. Cria sozinho o cenário, figurino e todos os objetos ou elementos do espaço cênico. Utilizando elementos da realidade (objetos, espaço e indivíduos que não são atores profissionais), ele os faz de forma tal que perdem completamente a relação com a realidade de seu uso cotidiano. Segundo ele, a arte só tem sentido de existir como contradição da vida social, da política e do poder. Ele diz ainda que é preciso abraçar toda a arte para compreender a essência do teatro. A arte do teatro se apóia na literatura, drama, artes visuais, música, dança e arquitetura.

Kantor se apropria dessa idéia e dá os manequins aos seus atores como referência. Os manequins presentes em "La Classe Morte"2 parecem ter vida expressa em seus olhos, porém sem poder se comunicar com o mundo exterior.

A ruptura com a lógica realista é visível nas obras de Kantor e Duchamp. A redefinição da função do objeto, que se transforma em elemento importante em suas obras, é mais um dos aspectos que mostram a influência do surrealismo e do dadaísmo. Foi com os dadaístas que pela primeira vez na história o objeto apareceu liberado da sua função vital.

Kantor trabalha na esfera do subconsciente e do automatismo, conceitos apregoados pelos dadaístas e surrealistas. Seus espetáculos são baseados na técnica do sonho, em que a ação é a repetição. Nesse sentido, podemos mesmo dizer que o ator

\footnotetext{
${ }^{2}$ Espetáculo teatral "La Classe Morte", de Tadeusz Kantor, ou le nouveau traité des mannequins au théâtre - Cricot 2 de Cracovie.
} 
para Kantor se torna mais um de seus objetos. Seu espetáculo possui a estrutura de um sonho, principalmente a partir da peça já citada "La Classe Morte". Por meio desse espetáculo ele mostra os princípios do seu teatro e a importância do objeto em cena, e afirma que os objetos mais simples, mais pobres, são os mais "disponíveis" para a obra de arte.

Segundo Duchamp, a obra não deve ser fruto do gosto estético, mas de cálculos, não devendo ser fruída como uma pintura, mas entendida nas relações simbólicas subjacentes a ela. Por essa via, a antiarte de Duchamp é, na verdade, a exigência de autenticidade artística levada a tal limite que quase torna a arte inviável. A partir de uma visão discordante da arte vigente, Duchamp assume uma nova atitude diante dela. Para ele, a criação não poderia ser considerada como um produto estético, mas como uma coisa totalmente liberada, livre da moldura imposta pelo aspecto retiniano. Considerando que o gosto estético é fruto de um mero hábito, Duchamp explica sua opção dizendo que a antiarte foi, sobretudo, colocar em questão o comportamento do artista tal como as pessoas o viam.

Assim, renunciando a toda estética, no sentido ordinário da palavra, Duchamp, por meio da obra "O Grande Vidro", aponta para o esfacelamento do objeto em função de uma construção e de um ordenamento do olhar cujo foco não se localiza mais na representação da figura. A obra volta-se, antes, para uma relação espacial, na medida em que cria uma superposição de perspectivas em relação ao seu quadro. Essa obra esvazia-se de pintura para chamar a atenção para o movimento do olhar: ler e compreender uma obra de arte, enfim, relacionar-se com ela.

Octávio Paz assim descreve o Grande Vidro:

O quadro de Duchamp é um vidro transparente: verdadeiro monumento é
inseparável do lugar que ocupa e do espaço que o rodeia: é um quadro
inacabado em perpétuo acabamento. Imagem que reflete a imagem daquele
que a contempla, jamais poderemos vê-la sem que nos vejamos a nós
mesmos. Em suma o poema e a pintura afirmam simultaneamente a ausência
de significado e a necessidade de significar e nisto reside a significação de
ambas as obras. (PAZ, 1990, p. 47)

Com essa citação podemos perceber que o espaço para Duchamp tinha sua devida importância. $O$ Grande Vidro foi criado para um determinado lugar. A escolha de espaços que permitiam diferentes relações entre os objetos e o espectador ou que fundiam espectador e obra torna-se bastante significativa. Paz nos descreve o vidro 
como um espelho que reflete quem está vendo a obra para que o próprio espectador esteja presente na obra de Duchamp.

O espaço era visto como um recipiente neutro no qual se misturavam objetos e formas, sendo também objeto de criação para nossos artistas.

Ao observar os espetáculos de Kantor, podemos perceber elementos que se repetem como cruzes, objetos com referências a cerimônias religiosas, escadas, máquinas, soldados, armas, guarda-chuva, malas, bonecos, cadeiras, tudo em preto e branco. A valise é um desses objetos que parecem não pertencer a nenhum personagem, mas, ao mesmo tempo, pode estar com qualquer um (signo de viagem). O Padre a utiliza para indicar a morte de um dos personagens, "signo da morte ela é também o signo da grande viagem sem retorno" (BABLET e ERULI, 1983, p. 250). Em cena, para que o indício de morte fique claro, a cabeça daquele que morreu (personagem Adás) fica entre o monte de terra, a cruz e a valise, assim não resta dúvida, ele fará a viagem final.

Entre os vários objetos, percebemos que a estola é um daqueles que mudam de significado segundo sua utilização. Durante o casamento, o padre utiliza esse ornamento para exercer sua profissão, num determinado momento da cena, ele tira a estola de seus ombros e envolve com ela as mãos dos noivos, objeto simbólico, cuja cor preta mostra que se trata de uma cerimônia mortuária. Após essa cerimônia, a noiva deixa cair a estola no chão, depois de ser pisoteada, então, Kantor, ele mesmo, a junta e a deposita em uma cadeira:

Eis que a estola vira agora um acessório de teatro desprovido de todo valor emocional. Em seguida o padre volta para buscar sua estola. Kantor a indica com um gesto. A emoção se rompeu, a ilusão teatral foi desvendada. Agora tudo pode recomeçar. (BABLET e ERULI, 1983, p. 251)

Percebemos aqui, que a estola é o referente, significa e é significante. No primeiro momento ela significa o casamento, em seguida significa morte, passando a ser, finalmente, um acessório a mais na cena.

A utilização de materiais bélicos também foi um ponto que chamou a atenção. Assim como Duchamp, Kantor também se utiliza desse tipo de material, como, por exemplo, a cama, que pode ser lugar de descanso ou de tortura, e a máquina fotográfica, que se transforma em metralhadora. 
Temos que levar em conta que os dois vêm de um pós-guerra, e esses materiais, assim como as máquinas de tortura, estão muito presentes em suas cabeças. É evidente que, para cada um deles, a relação é diferente, o tratamento do objeto tem um determinado sentido.

No espetáculo “La Poule D’Eau”, de Tadeusz Kantor, vamos encontrar uma máquina de tortura. Segundo ele, as máquinas ajudam a eliminar o jogo psicológico dos atores em cena. Em seu espetáculo mais famoso, "La Classe Morte", encontramos a máquina de ganhar bebê, que faz conjunto com o berço mecânico embalando constantemente duas bolinhas, provocando um barulho infernal. E a roda de bicicleta tão famosa, obra de Duchamp, é encontrada também como um objeto corriqueiro nos espetáculos de Kantor. Em entrevista com Denis Bablet, quando perguntado sobre a roda, Kantor afirma que já a utilizava muito antes de saber da existência de Duchamp, mas afirma que Duchamp é, para ele, um dos maiores artistas do século.

Temos tanto nas obras de Kantor como nas de Duchamp um despertar do espectador como sujeito construtor de significados. O artista passa a ser o portador de significados ou situações significantes a serem lidas como arte. $\mathrm{O}$ ato criador não é executado pelo artista sozinho; o público estabelece o contato entre a obra de arte e o mundo exterior. Sob essa ótica é interessante, pois, evidenciar que a criação dos readymades, ao recorrer a esse princípio, rompe definitivamente com a noção tradicional de valor artístico. No tratamento das várias significações da morte, se encontra mais um ready-made de Kantor, que trabalha com a noção da morte, mas não com o sentido fúnebre. O próprio autor explica: “A morte, para mim, é um ready-made. É o inimaginável. Experiência pela qual ninguém pode dizer que já passou. Eu não imito a morte, eu manipulo seus signos”. (KANTOR apud SCARPETTA, 2000, p. 89).

É, portanto, na manipulação desses signos que Kantor nos mostra a utilização dos ready-made, assim como em seus espetáculos, em que mistura objetos levados pelo acaso. Mas em um aspecto, segundo Amey, eles se distanciam:

Kantor se separa de Duchamp, com referência a utilização dos ready-mades, lá onde Duchamp quer dar uma resposta a arte, Kantor quer dar uma resposta a realidade; impossível compreender o gesto de Duchamp sem a prioridade da arte, enquanto em Kantor, a arte vem posteriormente, como um reencontro... Sua ambição não é mostrar ou comunicar o ready-made, de provocar a questão da arte lhe designando como arte, mas de integrar como um modo de sua teatralidade, que refere-se tanto ao texto como a memória, etc. (AMEY, 2002, p. 196) 
Se na sociedade industrial, os objetos utilitários são sempre criados para significarem a si mesmos, sua função utilitária, podemos dizer então que para os dois artistas há sempre um sentido que transborda os objetos. Para Kantor os objetos prontos ou construídos na cena não imitam, eles são. Para Duchamp a originalidade não estava em colocar um objeto pronto na obra de arte, mas em fazer do objeto uma obra de arte por decreto.

Os objetos nas obras de Duchamp reclamam o valor real da arte. Ele também se sente à parte neste mundo da arte retiniana. Através do quadro $\mathrm{Nu}$ descendo uma escada ele inicia sua rebelião contra a pintura visual e tátil. Como observa Otávio Paz "Duchamp é o artista que exerceu maior influência em nosso século, por sua obra que é a própria negação da moderna noção da obra". (1990, p. 07)

Na concepção de Duchamp, a função da obra de arte é estabelecer relação com a realidade, que não é dada de antemão, mas que se constrói a partir do movimento do olhar do observador. Portanto, é hora de buscar inspiração para a arte em outras direções, seja nos moldes científicos, na indústria ou na literatura. Nesse sentido, Duchamp se aproxima do hibridismo, idéia fundamental em sua obra, dando-lhe um sentido extrapictural, com a união da pintura e da escritura.

$\mathrm{O}$ século XX testemunhou transformações radicais na prática das Formas Animadas e nas múltiplas maneiras de se teorizar sobre ela. Mas, se os artistas deste século orientam cada vez mais sua prática na direção das formas que levam ao boneco é antes de tudo porque este representa uma alternativa para a cena naturalista. ${ }^{3} \mathrm{~A}$ partir dos anos 70 as experimentações dos bonequeiros confundiram-se cada vez mais com o movimento "performance art" e nasce então a tendência mais radical chamada "Teatro de Objetos" provocando uma revolução para redefinir o boneco e seu campo de expressão.

Os novos aspectos "representativos" de um Teatro de Bonecos, redefinido como Teatro de Objetos, produziram uma focalização mais acentuada sobre o manipulador ou o performer, que ocupa cada vez mais o papel central no espetáculo. A primeira imagem de um objeto em cena nos remete sempre ao que ele é na verdade, o referente. Aos poucos e à medida que recebe movimentos, o objeto começa a modificar-se, sendo esta

\footnotetext{
${ }^{3}$ Craig - O dramaturgo propõe a substituição da forma realista de representação, sugerindo a presença de "formas simbólicas", prenunciando, portanto, um teatro plasticamente mais elaborado, visual. Na verdade, estas proposições, em Craig, nascem de uma insistente recusa ao realismo como arte. "Creio que virá o tempo em que poderemos criar obras de arte do teatro sem nos servirmos dos atores [...] e as máscaras o substituirão num futuro próximo." In: CRAIG, Edward Gordon. A Arte do Teatro. Lisboa: Arcádia, 1963.
} 
a tarefa do performer ou manipulador. Assim um objeto a partir de diferentes significantes pode trazer a cena múltiplos significados.

São diversos os espetáculos em que Kantor se utiliza de objetos ou figuras de cera nos levando a pensar no Teatro de Formas Animadas. O Teatro de Objetos propõe um olhar diferente para o mundo que nos rodeia. Para esse tipo de teatro, quando escolhemos um determinado objeto, ele será eleito como algo que ganhará movimento e vida, levando o espectador a apropriar-se da ficção que lhe permite percorrer o simbólico. Para que esse objeto tenha presença cênica, será necessária uma série de experimentações, partindo de seu uso cotidiano para modificá-lo, alternando possibilidades, trabalhando seu ponto de equilíbrio e as características que lhe são próprias. A mudança do ponto de equilíbrio de um objeto faz com que sua função original se modifique. O movimento neste novo eixo nos dá impressão de vida em seu desequilíbrio; com isso, o público passa imediatamente a vê-lo como um ser vivo (humano), procurando identificar cabeça, olhos, boca, membros, e muitas vezes, idade e sexo. Nesse momento, a magia do objeto em movimento foi lançada, ele adquire vida e seu comportamento será determinado pelo ator manipulador. Para melhor explicitar esta idéia, trago como exemplo o espetáculo El avaro, de Molière do grupo Tàbola Rassa da Espanha. Neste espetáculo, os atores se utilizam de torneiras (referente) que se transformam no decorrer do espetáculo, através do texto, do figurino, das ações, da iluminação e sonoplastia, em novos referentes (pai, filho, namorada) levando a uma multiplicidade de significados (avareza, ciúme, amor).

Vimos no decorrer deste artigo os vários significantes e significados do objeto para as Formas Animadas e para os nossos referidos artistas, Duchamp reivindicando mudanças no olhar sobre a arte e Kantor se utilizando do objeto para enriquecer sua arte, da maneira mais simples que possa existir, porque o objeto segundo Kantor simplesmente é, está aí sua beleza.

\section{REFERÊNCIAS:}

AMEY, Claude. T.Kantor - Theatrum litteralis. Paris:L'Harmattan, 2002.

BABLET, Denis. D’Eduard Gordon Craig au Bauhaus. In : Le Masque du Rite au Théâtre. Paris: CNRS, 1985. 
. Tadeusz Kantor - Les voies de la création théatrale XI. Paris: Centre National de la Recherche Scientifique, 1983.

BARTHES, Roland. A Aventura Semiológica. São Paulo: Martins Fontes, 2001.

CABANNE, Pierre. Marcel Duchamp: engenheiro do tempo perdido. São Paulo: Perspectiva, 1987.

ERULI, Brunella. Una Temporada en Charleville. In: PUCK n. 2 - Las Marionetas y Las Artes Plasticas. Charleville-Mézières: Institut International de la Marionnette/Centro de Documentación de Títeres de Bilbao, 1991.

KANTOR, Tadeusz. Le Théâtre de la Mort. Textos reunidos por Denis Bablet. Paris: L'age D'home, 1977. . Leçons de Milan. Paris: Actes Sud - Papiers, 1990.

PASKA, Roman. Alternatives teatrales. Charleville-Mézières: Institut International de la Marionnette, 1999.

PAZ, Otávio. Marcel Duchamp-Castelo da Pureza. São Paulo: Perspectiva, 1990.

SANT'ANNA, Afonso Romano de. Desconstruir Duchamp. Rio de Janeiro: Vieira \& Lent, 2003.

SCARPETTA, Guy. Kantor del teatro a la pintura y a la inversa. In: PUCK $n .2$ - Las Marionetas y Las Artes Plasticas. Charleville-Mézières: Institut International de la Marionnette/Centro de Documentación de Títeres de Bilbao, 1991.

Kantor au Present. Paris: Actes Sud - Papiers, 2000.

UBERSFELD, Anne. Para Ler o Teatro. São Paulo: Perspectiva, 2005. 